\title{
Open Source Software: A Big Leap in the Computer Education
}

\author{
Amandeep Singh \\ Dept of Management \& IT \\ SSICMIT,Badhani \\ Pathankot,India
}

\author{
R.K Bansal, Ph. D \\ Dean,Research \\ Guru Kashi University \\ Talwandi Sabbo, Bathinda
}

\author{
Neetu Jha \\ Dept of Computer Science \\ Army Public School,Mamun \\ Pathankot,India
}

\begin{abstract}
We examine the appearance of open source software in computer science education. We will undertake with a concise tutorial on open source software introduction, including a depiction of major popular open source licenses. Later we deliberate the use of open source software in education discipline. We Present some advantage of open source software in the field of education Finally, we focus on the use of open source software in computer science education.
\end{abstract}

\section{General Terms}

Free and Open Source Software.FOSS for education.

\section{Keywords}

Open Source Software, OSS Licenses. OSS For Education, FLOSS.

\section{INTRODUCTION}

The basic perception behind open source software is: When programmers can read, reorganize and modify the source code for a piece of software, the software emerge. People revamp it, adapt it and fix bugs. While the open source group accepts that this produces preferable programming over the conventional shut model, in which few software engineers can see the source and others should indiscriminately utilize a hazy square, proponents of proprietary software argue that this can't work commercially. Open source software is a catalyst that will restructure the industry, producing higher quality software at lower cost.

The rudiments of the Open Source Initiative are that Denoting software for which the original source code is made freely available and may be redistributed and modified.Open source burgeon in the technological community as a response to proprietary software owned by corporations.

If we Contrast Open Source Software with Proprietary software, Proprietary software is privately purchased and controlled. In the computer industry, proprietary is considered the adverse of open. A proprietary design or technique is one that is purchased by a company. It also implies that the company has not proclaimed specifications that would grant other companies to duplicate the product.

Universities/Educational institutions have driven to put their academic resources and services online, bringing the comprehensive community onto a common platform and awakening the interest of investors. Against continuing technical challenges, online education shows great asseveration. Open source software offers one approach to addressing the technical problems in providing flawless delivery of online learning.
Open source doesn't just mean free access to the source code. It also means that the license for the software shall not restrain any party from selling or giving away the software as a component of an aggregate software distribution containing programs from several different sources. The program must include the source code, and must allow distribution in the source code, as well as the compiled form ${ }^{[12][10]}$. Where some form of a product is not distributed with the source code, there must be a well-publicized means of obtaining the source code for no more than a reasonable reproduction cost, preferably downloading via the internet without any charge. The license should also not discriminate against any person or group or field, should be technology neutral and should not be specific to a product.

Open source programming is likewise alluded to as "free programming".In spite of the fact that the two are exchangeable under the Open Source Initiative's definition, there are a few contrasts around prevalent comprehension. At the point when promoting the "open source "approach we frequently depend on the practical properties of the open source code ${ }^{[2]}$. For instance, we may cite the software's reliability and high quality due to the peer review and rapid evolution of the source code.

The disparities lie in exactly who gets access to this source code and why they have access to it. When explaining free software we use a moral argument; rather than basing our argument on the benefits of the open source code, we purport the right everyone has to the source code. When we speak of "free software" we are referring to the freedom of the user to read, redistribute, reorganize, and use the source code rather than the lack of cost.

\section{LICENSING FOR OPEN SOURCE SOFTWARE}

An open-source software license is a type of license for computer software and other products that grant the source code, master plan or design to be used, modified and/or shared under defined provisions and circumstances. This grants end users to edit and reorganize the source code, master plan or design for their own customization, concern or recompense needs.As Open source software Initiative has approved 45 Open source software license.We will review to four license common to educational process that are as follows.

\subsection{GNU GPL}

The GNU General Public License (GNU GPL or GPL) is the most universally used free software license, which assure end users (individuals, organizations, companies) the freedoms to use, study, share (copy), and modify the software. 
Software that allows these authorities is called free software. The GPL allocates the beneficiary of a computer program the authority of the Free Software Definition and uses copy left to ensure the freedoms are conserved whenever the work is distributed, even when the work is changed or added to. The GPL is a copy left license, which means that derived works can only be distributed under the same license terms.

\subsection{GNU LGPL}

The GNU Lesser General Public License or LGPL (formerly the GNU Library General Public License) is a free software license advertised by the Free Software Foundation (FSF) ${ }^{[13]}$. The LGPL acquiesce developers and companies to use and integrate LGPL software into their own (even proprietary) software without being required (by the terms of a strong copy left) to release the source code of their own software-parts. The software under this license, like the GPL, is also CopyLefted, but unlike the GPL, can be linked to proprietary code with its own license.

\subsection{BSD}

BSD licenses are a family of permissive free software licenses, imposing minimal restrictions on the redistribution of covert software. The Berkeley Software Distribution License (BSD for short) is one of the most commonly used open source licenses. Approximately seven percent of the open source-licensed projects on the software repository Source forge use some form of BSD license ${ }^{[5]}$. MPL

The Mozilla Public License (MPL for short) is often portrayed as being the middle-ground between the strictness of the GNU General Public License (GPL) and the tolerance of the Berkeley Software Distribution License (BSD) ${ }^{[14]}$. It is not used anywhere near as broadly as either the GPL or the BSD licenses, but it flexible-ness and gracious drafting mean that it is becoming more popular. Following Table is having a comparison about the License.

Table 1. License Comparison of Software

\begin{tabular}{|l|l|l|}
\hline Factor & Open Source & Proprietary \\
\hline Cost & Mostly Free & Free or paid \\
\hline Copyright & $\begin{array}{l}\text { Licensed, credit } \\
\text { given to original } \\
\text { developer when } \\
\text { modified. }\end{array}$ & $\begin{array}{l}\text { Licensed by developer } \\
\text { only, licensing granted } \\
\text { rights to use }\end{array}$ \\
\hline $\begin{array}{l}\text { Source Code } \\
\text { Ownership }\end{array}$ & $\begin{array}{l}\text { No ownership } \\
\text { rights }\end{array}$ & $\begin{array}{l}\text { The developer owns the } \\
\text { rights }\end{array}$ \\
\hline $\begin{array}{l}\text { Source Code } \\
\text { Modification }\end{array}$ & $\begin{array}{l}\text { Anyone can } \\
\text { modify }\end{array}$ & $\begin{array}{l}\text { Only developers can } \\
\text { modify }\end{array}$ \\
\hline
\end{tabular}

Open source licensing and proprietary licensing have two very different goals in mind: The latter has turned into a game of making a profit, whereas the former is all about taking a basic idea and twist it into something bigger and better.

\section{OPEN SOURCE SOFTWARE \& EDUCATION}

Open source refers to both the approach and process of making program source code openly available. Users and developers have access to the core designing functionalities that enable them to reshape or add features to the source code and revamp it. Extensive collaboration and apportionment are central to the open source movement .Educational institutions have driven to put their academic resources and services online, lead the global community onto a common platform and awakening the interest of investors ${ }^{[9]}{ }^{[3]}$. Against continuing technical challenges, online education shows extreme promise.

Open source software offers one approach to addressing the technical problems in providing excellent delivery of online learning. Open source refers to both the concept and practice of making the program source code publicly available.. Many groups have been established to develop and promote open source software as a feasible technological solution for educational uses ${ }^{[3]}$. By using open source software, schools can free themselves of licensing costs and put their (often scarce) resources to other uses. As one might expect, the focus is on Linux, and tools that work on Linux platforms. A snapshot of the current proprietary software environment in education reveals some fascinating drivers.

- Tight budget has focused attention on software acquisition cost and total cost of ownership ${ }^{[15]}$

- Lack of innovation .Learning technology has not lived up to its potential to improve learning and some enablers of a more effective model

- Software design patterns, development technologies and standards have evolved in a way that ease modular, interoperable software component.

- Substantial cultural appeal of open source in academia

We observe many of these drivers and enablers beyond the context of higher education. Perhaps the cultural appeal in the academia represents the tipping point for a powerful movement unique to colleges and universities. Following Table Having Lists of Free and Open Source Software used in Education 
Table 2 List of Free and Open Source Software used in Education

\begin{tabular}{|c|c|}
\hline \multicolumn{2}{|c|}{ Free And Open Source Software in Education } \\
\hline Software & Description \\
\hline Office Suite & $\begin{array}{l}\text { OpenOffice.orgis a complete office suite, } \\
\text { including. } \\
\text { - Word processor } \\
\text { - Spreadsheet } \\
\text { - Presentation } \\
\text { - Database }\end{array}$ \\
\hline $\begin{array}{l}\text { Web } \\
\text { Browser }\end{array}$ & $\begin{array}{l}\text { Mozilla Firefox a secure and efficient web } \\
\text { browser with } \\
\text { - Pop-up blocking } \\
\text { - Tabbed browsing } \\
\text { - Many useful extensions }\end{array}$ \\
\hline Email & $\begin{array}{l}\text { Mozilla Thunderbird is an email client that } \\
\text { does } \\
\text { - Spell checking } \\
\text { - } \quad \text { anti-spam filtering } \\
\text { - RSS feed reader }\end{array}$ \\
\hline $\begin{array}{l}\text { Photo } \\
\text { Retouching } \\
\text { / Bitmap } \\
\text { Software }\end{array}$ & $\begin{array}{l}\text { The GIMP is a professional photo retouching } \\
\text { that } \\
\text { - Does photo retouching and } \\
\text { exporting to the Web } \\
\text { - Uses layers, filters, plugins } \\
\text { - Does rendering with complex effects }\end{array}$ \\
\hline $\begin{array}{l}\text { Vector } \\
\text { Drawing }\end{array}$ & $\begin{array}{l}\text { Inkscapeis a professional vector drawing } \\
\text { software that can do } \\
\text { - Logo, clip art and schema design } \\
\text { - Rendering without pixelization at } \\
\text { - } \quad \text { Exy zoom level } \\
\text { - }\end{array}$ \\
\hline $\begin{array}{l}\text { Desktop } \\
\text { Publishing }\end{array}$ & $\begin{array}{l}\text { Scribusis a professional desktop publishing } \\
\text { software that allows. } \\
\text { - } \quad \text { Page layout of complex documents } \\
\text { (newspapers, brochures,...) } \\
\text { - } \quad \text { Print shop quality output } \\
\text { - } \quad \begin{array}{l}\text { Professional management }(\mathrm{CYMK} \\
\text { colors, color management,...) }\end{array}\end{array}$ \\
\hline $\begin{array}{l}\text { Media } \\
\text { Player }\end{array}$ & $\begin{array}{l}\text { VLC is a media player that } \\
\text { - Play video files and streaming } \\
\text { - Plays audio files and streaming } \\
\text { - Supports a wide variety of audio and } \\
\text { video formats }\end{array}$ \\
\hline $\begin{array}{l}\text { Web Page } \\
\text { Editing }\end{array}$ & $\begin{array}{l}\text { NVUis a Web page editing software with } \\
\text { - } \quad \text { WYSIWYG editing } \\
\text { - } \quad \text { FTP file transfer manager } \\
\text { - } \text { CSS style sheet editor }\end{array}$ \\
\hline
\end{tabular}

\section{LEARNING AND DIGITIZATIsON}

The Digitization of education is a almost new aspect that has transformed the education sector. Institutions have endorsed the digitization process through

- Online Courses

- $\quad$ Education portals

- Virtual universities

Online courses are those in which students and instructors are not in the same physical space at the same time; instead, they interact online ${ }^{[2]}$. Some Courses are adjacent of renowned traditional universities. The Parent university name acts as a powerful draw for online courses.

An Education portal is a website that's designed to provide educational services. The term portal was historically used to describe a port or locale of multiple loading and offloading enterprise. It is now used more widely to describe a multifunctional website that includes public and private sections, data retrieval and submission tools, illustrate content, and often links or connections to education related systems or services.

Virtual Universities are the best example of online education. A virtual university provides higher education programs through electronic media, typically the Internet. The Idea behind the virtual university is that multiple academic institute assimilates related courses into the program via $\mathrm{A}$ single virtual university ${ }^{[2]}$.

The internet offers connections to merge educational and economic goals on a globally accessible platform. Most universities and institutes of education sector reckon on software vendor for support for a virtual learning environment that deliver online learning components. An adoption of open source software for educational institutions is enable the pool, their financial and technical resources.

\section{IMPACT OF OPEN SOURCE SOFTWARE}

Open Source Software has emerged as a feasible solution to match the balance between requirements and resource for universities. Many Top Class universities opted for open source software as their university curriculum. Some of the benefits garnered by Universities are

\subsection{The absences of license fee}

As open source programming is permitted free, they have the immediate playing point over the exclusive programming for which colleges need to pay inordinate expenses to programming organizations.

\subsection{Unceasing Improvement}

Voluminous Collaboration guarantee that the nature of programming will be continue Improving. Volunteers over the planet help unreservedly to the ventures. 


\subsection{Tax Benefits}

Government assumes critical part to help up the open source programming. In Some nations government advertising open source programming by giving assessment allotment strategies to support up open source venture ${ }^{[2][9]}$.

\subsection{Bug-Fixing}

All product discharges hold bugs. Surely, the individuals creating the product will have blotched and exchange with anything clear, however, any advancement group has just such a great amount of time in which to test a bit of programming before it is discharged. At the point when a bug is seen in exclusive programming, the main individuals who can settle it are the first designers, as just they have an entry to the source code. Open source programming is diverse. As a substantial number of clients can get to and change the code, bugs incline toward being more unmistakable and all the more quickly remedied. One of the trademarks of the open source development is that given enough awesome, all bugs are shallow.

\subsection{No Vendor lock-in}

IT Managers in associations confront the steady inconvenience when managing seller lock-ins'. Absence of versatility, unmanageable permit charges and significance to alter programming are a percentage of alternate embodiments. Utilizing open source programming provides for you. More opportunity and you can successfully address all these disservices ${ }^{[6]}[15]$

\subsection{Abundant Support}

IT supervisors in associations confront the consistent disturbance when managing seller lock-ins. Absence of transportability, costly permit charges and imperativeness to radio programming are a percentage of alternate disservices. Utilizing open source programming provides for you. More opportunity and you can adequately address all these disadvantages you will get bounteous backing when you utilize open source programming. Open source help is for the most part unreservedly accessible and could be effortlessly gotten to through online groups. There are additionally numerous programming organizations that give free online help and likewise different levels of paid backing. Most associations who make open source programming results additionally help support and backing. ${ }^{[13]}$

\section{CUSTOMIZATION}

Closed source applications can only be customized or adapted within the scope provided by the original vendor but never outside its edges. Open source applications may be customized by anyone with the requisite skill. Thus, open source software can be promptly adapted to meet specific user needs. Even if you cannot program yourself, if you would like something added or customized you can generally pay an accordingly skilled software developer to do it for you. The introduction of competition into the market for customizations, as observed in the bug-fixing section above, forces suppliers to offer high quality at an ambitious price. For businesses or educational institutions, the ability to customize source code may enable renovation to the best practice provided by default installations, therefore improving efficiency and possibly providing a competitive advantage. ${ }^{[14][15]}$

The main potential fault of open source project for education become evident during their implementation.Lots of issue and challenges can be raised during the Implementation. Most of the open source products are not always compatible with existing software components.

The most alarming factor to consider is possible loss of support. Typical users are not interested in the possibility of source code ${ }^{[7]}$. They are more concerned with software usability. This is the reason proprietary software companies perpetrate resources to product documentation and customer support. The inadequacy of commercial incentives in many open source project trims some contributor intensity.

\section{ALTERNATIVES OF PROPRIETARY SOFTWARE}

Open source software has come a long way and has matured through the years. Nowadays, you can easily find free open source applications that can serve as a substitute to many of the popular proprietary software commonly used today.

Table 3. Alternatives of Proprietary Software

\begin{tabular}{|c|c|c|}
\hline Category & $\begin{array}{c}\text { Proprietary } \\
\text { Component } \\
\text { /Software }\end{array}$ & FOSS Alternative \\
\hline OS & $\begin{array}{c}\text { Microsoft } \\
\text { Windows }\end{array}$ & Linux/MAC/Solaris \\
\hline $\begin{array}{c}\text { Automation } \\
\text { Software }\end{array}$ & MS Office & Open Office/Star Office \\
\hline Image Editor & Photoshop & Photo Filtre/ GIMPshop \\
\hline $\begin{array}{c}\text { Image } \\
\text { Processing }\end{array}$ & Matlab & Scilab \\
\hline $\begin{array}{c}\text { Web designing } \\
\text { FrontPage or } \\
\text { DataBase }\end{array}$ & $\begin{array}{c}\text { Oracle, Sybase } \\
\text { or Microsoft }\end{array}$ & $\begin{array}{l}\text { MongoDb, MySQL, } \\
\text { MaxDB and PostgreSQL }\end{array}$ \\
\hline Web Server & IIS/PWS & $\begin{array}{l}\text { Apache - HTTP web } \\
\text { server }\end{array}$ \\
\hline Web Container & $\begin{array}{l}\text { Microsoft } \\
\text { Serve 2005 }\end{array}$ & Tomcat web server \\
\hline Browser & IE & Mozilla, Opera \\
\hline $\begin{array}{l}\text { Programming } \\
\text { Language }\end{array}$ & C.C++,Cobol & Java,Phython,Perl,PHP, \\
\hline
\end{tabular}

Although these applications will take some time getting used to the first time you use them, but eventually you will find 
that they can do most, if not all, of the things their proprietary correspondent can do.

\section{CONCLUSION}

We Present our experience in using entirely open source software tools for teaching and research and we examine at why open source projects might propose to students and professor. Teacher all over the world reassure their students to get more involved in creating blogs answer other interactive web applications to enhance peer communication in and outside the classroom ${ }^{[4]}$.

Open Source Products have gained extensive currency in the dimension of higher education. The question remains nevertheless: what is the future of open source software in higher education. From the Commercial point of view open source project are taking their first tentative step in to the market. This might be good news for universities because it would remove the threat of market monopolization, but to measure up to industry standards open source project needs more sophistication. Adapting the open source software for education is a challenge ${ }^{[10]}$. Some of the few fallacies that have to be yet overcome

- Awareness of OSS

- The Politics of Payment

- The Dynamics of Change in Schools

- Understanding Software Choice as an Ethical Consideration

- Technical Personnel

Those of us familiar with OSS can see the clear benefits it holds for education. The fiercely lower cost of the software along with greater freedom in how it is used and how it is shared make it a valuable resource for schools. With the OSS and its related know-how promptly available, acquiring and installing OSS is the easy part. The real challenge is in helping educators, administrators, and technical support personnel realize the huge potential OSS holds for teaching and learning and in planning an appropriate implementation approach that Addresses the sociopolitical hurdle we discussed earlier.

We believe that both open source software and proprietary software have an important role to play in the computer industry of the future ${ }^{[12]}$. While We do not advocate only use open source software for education, we believe the hazards of open source software is essential for student success. As future work .

Future research on how to plan and implement the open source software in education.

\section{REFERENCES}

[1] http://www.oss- watch.ac.uk/resources/modbsd.html

[2] http://www.educause.edu/ero/article/open-sourcesoftware-education

[3] Col (Dr. Rakesh Sharma), Sonyamol Koshy."Open Source Software in Education". In IJMBS June 2011

[4] List of Proprietary Software(From Wikipedia, The free encyclopedia http://en.wikipedia.org/w/

[5] Free BSD Online Document Accessed Aug 31,2009,http://www.freebsd.org

[6] Perceived Disadvantage of open source Model," http://eu.conecta.it/paper/perceived_disadvantage.html

[7] http://www.theopenlearningcentre.com/resources/knowle dgebase/benefits-of-oss.html.

[8] Brenda Chawner"'Free/Open Source Software New Opportunity, New Challenges.

[9] Lakhan SE; Jhunjhunwala K. Open Source Software in Education. EDUCAUSE Quarterly. 2008;31(2):32-40

[10] Gunjan Kotwani, Pawan Kalyani "Realistic Implementation of OSS in School Education"(2008)

[11] Girija Krishnaswamy and Dora Marinova" FOSS in Education: IT@School Project, Kerala, India”2011

[12] H. Wang and C. Wang, "Open Source Software Adoption: A Status Report," IEEE Software, vol. 18, no. 2, Mar./Apr. 2001, pp. 90-95

[13] Dan R. Lipşa, Robert S. Laramee" Open Source Software in Computer Science and IT Higher Education: A Case Study" IJACSA Vol.2,No.1,January2011

[14] Mamta Malik "Role of Open Source In Higher Education in 2007

[15] Amandeep Singh, Neetu Jha" Foss :A Challenge to Proprietary Software" IJCST Vo 1. 4, IS Su e3, Ju 1 y- Se pT2013 